\title{
A New Book of the Dead: Reflections on the Near-Death Experience and the Tibetan Buddhist Tradition Regarding the Nature of Death
}

\author{
Kenneth Ring, Ph.D. \\ University of Connecticut
}

ABSTRACT: There are many similarities between Tibetan Buddhist teachings on death, as reflected in The Tibetan Book of the Dead (Trungpa and Freemantle, 1975), and a perspective based on the modern study of near-death experiences (NDEs)-but also important differences. In view of these differences, a more appropriate comparison might involve historical cases of Tibetan NDEs and contemporary Western accounts. A tradition of NDEs in Tibetan culture, the das-log experience, affords such a comparison. Modern NDEs differ from das-log experiences in ways that reflect their cultural context, and may provide the foundation for a new Book of the Dead especially fitted to the existential and planetary concerns of our own time.

What can we say about the nature of death from the perspective of modern Western scientific research? My jumping off place for this question will be-to no one's surprise, I'm sure-the research that has been conducted, largely in the West, for almost two decades now, on the near-death experience (NDE). Most readers of this Journal, I

\footnotetext{
Kenneth Ring, Ph.D., is Professor of Psychology at the University of Connecticut. This article is adapted from a presentation to the International Conference on Healing: Beyond Suffering or Death, Montreal, Canada, June 22, 1993. Reprint requests should be addressed to Dr. Ring at the Department of Psychology, University of Connecticut, Storrs, CT 06269-1020.
} 
assume, will know something about this extraordinary phenomenon, so I will not take any time here to describe its familiar features.

Still, just to be clear as to what it is, I am talking about an experience that has been reported by many thousands of persons who have gone to the brink of physical death, or even over it temporarily into the first stages of clinical death, and have then returned to life. And, as the world now knows, such persons tend to describe a remarkable experience, remarkable both for its content and for the fact that it so astonishingly similar, by and large, from one person to another. For all the controversy about the meaning of the experience itself, it is enough to note here that it is now well established and abundantly documented. The question is: what does it tell us about the nature of death?

Obviously, since these near-death experiencers have only been clinically dead and not biologically dead, we are not permitted to draw any logical conclusions from the NDE itself about what happens after physical death. The NDE gives us a direct and literal insight only into what appears to happen during the first stages of death when the heart stops, respiration ceases, there is a rapid drop in blood pressure, and so on.

Clearly, however, that vision of the entrance hall into death paints a seemingly very attractive picture of death itself and many persons who have become familiar with the NDE have certainly drawn a great deal of comfort from it. Moreover, virtually everyone who has this experience becomes convinced that some form of conscious existence awaits us after physical death, and that the NDE is a preview of this existence. This is so regardless of whatever their prior beliefs on this question may have been, and anyone who has listened to this consistent and indeed insistent testimony cannot help but be impressed by its sincerity and tone of inner certitude.

Nevertheless, empirically, it's difficult to justify going beyond this point. The NDE trail leaves off after a while and those who survive this experience return to tell their tales of what they have seen. Those whose testimony we really need on this matter, the ones who do not survive, have of course no tales to tell. Thus, the NDE, while it may illuminate the mystery of death, in the end, doesn't really solve it for us. And so we remain, as it were, still in the dark, although with the hope that one day we ourselves might find our own answers in the light.

Understandably, many persons have felt that it is possible to go beyond the inherent limitations of NDE research by joining its findings to already existing spiritual teachings or traditions that purport to tell us not only of the initial moments of death but of the entire 
journey into the after-death realms. Such persons, naturally, have been led to this approach because they have seen clearly that what the NDE implies about the first moments of death tends to be highly congruent with the teachings of various spiritual traditions. Therefore, given this kind of overlap between the findings of NDE research and these spiritual teachings, it is hard to avoid the inference that the NDE itself points to the possibility that the entire journey into death may indeed conform to the canons of these spiritual traditions. Thus, though unsought and ultimately unnecessary, NDE research has been used as a sort of empirical support for these teachings.

And just here, of course, we make the linkage between the great tradition of Tibetan Buddhism and its teachings on death, as reflected especially in The Tibetan Book of the Dead (Trungpa and Fremantle, 1975), and the NDE. A few words on this connection are certainly in order.

As many of you will be aware, several commentators (e.g., Becker, 1985; Carr, 1993; Grof and Grof, 1980; Grof and Halifax, 1977) beginning with Raymond Moody - the psychiatrist whose best selling book, Life After Life (1975), introduced the modern world to the near-death experience and gave us the very phrase we use for this phenomenonhave pointed to the numerous parallels that exist between the NDE and the The Tibetan Book of the Dead. And indeed, the noted lama, Sogyal Rinpoche, has performed the same service for us in his book, The Tibetan Book of Living and Dying (1992). In general, what these comparisons show is that there are many features of the NDE that are described as components of the experience of dying and the after-death bardo states in The Tibetan Book of the Dead. These points of seeming equivalence are particularly evident in the last bardo-usually called in English the bardo of becoming - and no one familiar with the literature on NDEs could fail to spot them when reading the The Tibetan Book of the Dead. Indeed, this is so obvious and well-accepted a point that I will not dwell on it further here; it is enough just to remind you of it.

Still, before exploring this linkage more deeply, I would like to add that there are some further points of correspondence here that are not well known, but should be brought out, at least briefly. For example, in the bardo of becoming, it is obvious that should efforts at liberation fail, the individual will eventually find himself drawing ever closer to reincarnation, which is of course an integral part of the teachings of Tibetan Buddhism. What many persons-even those already conversant with NDE literature in general-are not aware of is that recent research suggests that the great majority of near-death experiencers, 
following their NDE, also come to embrace a reincarnationist view of the life cycle. This has now been found in three separate studies (viz., Ring, 1992; Sutherland, 1992; and Wells, 1993) and shows that the overall level of belief in reincarnation among NDErs appears to be about three times greater than that of the general population in the United States (23\%, according to a Gallup poll; see Gallup and Proctor, 1982). Furthermore, there is some evidence that this reincarnationist shift is experience-based and often reflects insights given during the NDE itself or in its experiential aftermath. Thus, here, too, we find further evidence linking the traditional teachings of Tibetan Buddhism on the nature of death with the revelations apparently vouchsafed during the NDE.

Yet, after noting these patterns of similarity, we shouldn't allow ourselves to be blind to the differences that are just as apparent but more often overlooked. In my opinion, these differences also have something important to teach us, and in the remarks to follow I would like to amplify on some of them.

According to tradition, the elements of The Tibetan Book of the Dead derive from the 8th century and are credited to Padmasambhava, who introduced Buddhism to Tibet, but were only brought to light and codified a few centuries later. In any case, this book has long served as a manual to help guide individuals through the dying process so that they can gain liberation or, failing that, at least achieve circumstances for a favorable rebirth. Though the description of the experiences in the bardos is said to derive from enlightened lamas and yogis who were directly aware of these internal states, what we have in The Tibetan Book of the Dead, as it came to be ritually used through the centuries, is largely a tradition-based teaching. This teaching treats the nature of the after-death, shows how to recognize the experiences in the bardos as essentially mental projections, and contains frequent exhortations to attain liberation by seeing into one's own true nature-essential emptiness-especially through complete identification with the Primary Clear Light.

With the NDE, of course, we have something very different. It is based not on scriptural tradition but on scientific research into the direct experiences of now tens of thousands of persons, mostly Westerners, who claim to know first-hand what it is like to die. Their collective stories present, I think, a rather different view of the death process than is to be found in The Tibetan Book of the Dead. True, the elements are often similar, as I have said, but they are organized in a different way by the bearers of this tradition - the NDErs themselves and especially the chroniclers of this tradition, NDE researchers and 
writers-and the resulting NDE narrative line tells a very different story with somewhat different implications.

After all, the narrative line in The Tibetan Book of the Dead begins with the encounter with the Primary Clear Light, then moves into the bardo of dharmata, with its fabled peaceful and wrathful deities, and finally into the bardo of becoming with its lonely and frightened individual being blown about in his mental body by the winds of karma, eventually to take rebirth in another physical body. The NDE, on the other hand, begins with a tremendously reassuring sense of peace and well-being, which eventually culminates with the glory of absorption by and merging with the light, but always ends with a return to the present physical body, often as a result of one's sense of subjective choice. The NDEr returns from death, then, and returns transformed, but the journeyer of The Tibetan Book of the Dead actually dies, either to be liberated or to be reborn into a new life some weeks later.

This being so, one is moved to ask whether there is anything in the Tibetan tradition that would actually provide a more appropriate basis of comparison to today's NDErs than what is given in The Tibetan Book of the Dead. And the answer is: there is. For the Tibetan culture has, in fact, its own distinct history of near-death experiencers, and furthermore, the stories of their experiences have been chronicled and are well known in Tibet, if little known to us in the West. Such persons are called das-log, which means "returned from death." The narratives of these persons, in their own cultural and historical context, and how the accounts of these experiences are used by their society, have a great deal to teach us about the relativity - as well as the universality of NDEs.

These accounts are not based on the revelations granted to great lamas or other spiritual figures, but come from ordinary men and women of Tibet who have nearly died but somehow revived. Here, of course, we see an immediate and undeniable similarity to our modern NDErs. Although, according to what I've read, the phenomenon can still be found among today's Tibetans, the heyday of these accounts and biographies about these persons stemmed from the early sixteenth to the mid-eighteenth century in Tibet.

The das-log experience in fact has many commonalities with modern NDEs, but its tone throughout is more negative and judgmental, and its mood often frightening to the point of terror. The key episodes center on a tour of hell and an encounter with the Lord of Death, Dharmaraja, who, after judging the individual, exhorts him to lead a moral life in conformity with the tenets of Buddhism, and, once 
returned, to spread the word among the living. The das-log indeed does appear to do this, and the literature based on these experiences helps to renew and reinvigorate these teachings. The das-log himself or herself even has a certain spiritual authority, which is conferred by his special personal experience and the evidence of his own moral zeal in everyday life. According to one writer, Lawrence Epstein, on the subject:

The major function . . of the das-log literature is just this: to teach or remind an audience of laymen who either may have known or had been accustomed to forget that the dogmas of Buddhism really work. The biographies of the das-log stress three things: suffering and impermanence, the vicissitudes of karma, and how these may be overcome. As such, they are concordant with the basic teachings of the sutras. . . . The das-log, however is more than just a teller of tales. He himself becomes a source of religious authority and an object of popular worship (Epstein, 1982, p. 21).

In short, the social function of the das-log in Tibetan culture is to help "keep the (Buddhist) faith."

Now all this material on the das-log-and the detailed personal accounts themselves, however they may have been modified for hortatory purposes by the scribes who have provided us with this literature, are fascinating-is very instructive on the ways in which these apparent NDEs come to have a form consistent with the general religious belief system of the culture in which they are embedded. Perhaps this is an obvious point, but what makes it more telling is that we have in our own Western tradition NDEs that are, almost point for point, the exact equivalent of the das-log experience in Tibet.

I'm referring to the medieval period from about the tenth to the thirteenth century in Christendom when very similar stories and a distinctive literary tradition based on them were well known. These tales, and their relationship to modern NDEs, were explored extensively by the American scholar, Carol Zaleski, in her excellent book, Otherworld Journeys (1987). In it, Zaleski emphasized that the medieval NDEr in the Christian tradition had riveting experiences in hellish and purgatorial realms, was confronted with a weighing of his or her good and evil deeds, and returned with a deep sense of the need to live in accordance with the moral teachings of the Church and inspired with a zeal to recount these visionary experience to others so that they, too, may be strengthened in their belief.

These medieval NDEs in the Western tradition and the das-log experience that was common in Tibet a few centuries later are not only 
structurally identical, but also reflect the imprint of the religious traditions that molded them and that, in turn, were strengthened by them to the extent that others heard and gave credence to such tales. In short, the faith of Tibetans was reinforced by recourse to the same kind of experience that Christians of another era had used to support their beliefs.

What are the lessons of these historical NDEs for us? For one thing, I think they show us that while the body of the NDE, so to speak, may be given by the brain, it is clothed in the garments of the culture. What I mean is, the overall form of the NDE may be very much the same because all human beings share a common biology. Therefore, the elements that comprise the experience of dying can be expected to show, over time and culture, a certain uniformity. But in the same way that all human bodies show the same structural similarities but can appear in very different dress according to one's time and culture, the NDE's surface appearance may be expected to show similar variations. Second-and I think this is important to emphasize-while medieval Western and traditional Tibetan NDEs may have had some astonishing similarities, both are very different from modern NDEs. And from this, a third thing follows: What contemporary NDEs have to teach us and the insights we derive from them differ in important ways from these traditional NDEs. And for that reason it is crucial, in my opinion, to focus precisely on the differences here and to resist the obvious temptation to assimilate these experiences into a kind of generalized universal atemporal model that obscures the special meaning of NDEs for our own time and planetary culture.

What of these contemporary NDEs and their particular relevance to this juncture in our planetary journey? To begin with, there is one aspect of modern NDEs that seems to set them sharply at variance with those I have already discussed, and that is the emphasis on love. Love is the primary energy of these experiences, as is well attested, and it is the essential message of the NDErs who are the embodied vehicles of this love. Their cry is simple: Love others, love yourself, love the earth, love life and the privilege of life, love God, the very energy and source of this love. The universe is not a cold, mechanical machine indifferent to our fate: it is stitched in a fabric of love, and we ourselves, being a part of the universe, are also made of this love. The NDErs want us to be aware of this, and to act on it.

Second, the sense of judgment from an external source, which was so evident in the earlier historical accounts and even in The Tibetan Book of the Dead, is largely absent in these modern narratives. Instead of judgment by the Lord of Death or a high tribunal, one stands in the 
presence of an all-accepting being of light and looks at one's life, in one's life review, simply with razor-sharp objectivity. And what you see with full awareness are the effects not only of your actions on others, but also the effects of every thought and every emotion, since they affect others, too, whether you have been aware of it or not. Needless to say, this can be a very humbling and painful experience, but it takes place, remember, in a context of compassionate understanding for why you have behaved as you did. And it is you who are doing the judging. And what you come to understand through this experience, as a number of writers on the NDE have already pointed out (e.g., Farr, 1993; Lorimer 1990; Reanney, in press; Sogyal 1993) is that there is only one person in the universe: you. You see that the Golden Rule is not merely a prescription for ethical conduct, it is how it works. Everything you do unto others you yourself experience, for in this state you become the very people you have hurt and the very people you have aided. It is, in short, an immediate intuitive understanding of the law of karma. And you also see this without guilt, and with the knowledge that all your so-called "sins" have been forgiven.

Third, because you are in a state where there is no sense of separation but only wholeness and interconnectedness, you come to appreciate that all of the world's divisions based on racial, national, ethic, or religious grounds no longer have the same meaning or force of allegiance for you. You can easily see the truth in many different religious traditions, for example, and what is universal in them. And it is these universal truths rather than sectarian dogmas that are revealed to you in this state, and which come to affect your outlook on life afterward. As a result, you are more likely, as many NDErs have said, "to feel at home at any church," and, in effect, to call all religions your own.

Finally, the NDE extinguishes, and seemingly permanently, one's previous fear of death. Death is seen to be an illusion of the senses and to exist only from a purely physical, external point of view. What is essential in us, however, is without birth or death, and is what is experienced when one encounters and becomes one with the Light and sees directly into the heart of eternity.

Most persons familiar with the now abundant literature on the NDE will recognize these as the common themes of today's NDEs. But why these particular themes, one may well ask?

I submit that the NDE always reflects the requirements of the times and is shaped by the prevailing culture in terms of its collective needs. In short, the NDE is not a purely endogenous phenomenon, but is in part called out by the zeitgeist. In this vein, we might assert, then, that although the ideals of liberation or salvation are still found in the religions of East and West and were leading motifs of earlier NDEs 
when such religions ruled their cultures, it seems that the dominant need of our time is for people to live in harmony with one another and all life; otherwise, we are likely to destroy one another and possibly irreparably damage our Mother Earth. The best way to abort this form of ecocide is for persons to experience egocide; that is, to realize that we are all truly one on this earth, that we are joined in love, and that our selfish, separative ways are going to have to be seen as ultimately grounded in illusion. And that we are in the end responsible for everything we do in life-and life is forever and does not terminate in death, which is only another illusion.

What we have in the NDE, then, somewhat in contrast to The Tibetan Book of the Dead, is an experience-based teaching about the nature of death (and life) that is emerging in our own time, founded on the testimony of thousands of ordinary people who have somehow secured the imprimatur of the priests of our era, those who wear the white vestments of the physician and scientist. These people collectively are writing a Book of the Dead fitted to the existential requirements of our time in history and our sense of a nascent planetary culture that is imperiled as never before by the tyranny of egos still caught in the delusion that they are real and separate entities.

This Book of the Dead, based on the narratives of today's NDErs, obviously doesn't supplant any others, but on the contrary can be combined with them in creative ways to meet the particular demands of our time and to speak to persons in the language and imagery appropriate to a modern planetary culture. Rinpoche's book (1992), for example, has done this beautifully, and his is truly one of these books for our time. And to the Tibetan tradition generally our debt is enormous and enduring since it always addresses itself to the fundamental issues of compassion, wisdom, and liberation.

But the collective wisdom of the NDE is also a resource for us at this time, providing us with a new and distinctive vision of death and the seeds for a harmonious way of life on earth-for all the earth. Therefore, let us not hesitate to learn from it and use it well.

\section{References}

Becker, C.B. (1985). Views from Tibet: NDEs and the Book of the dead. Anabiosis: The Journal of Near-Death Studies, 5(1), 3-20.

Carr, C. (1993). Death and near-death: A comparison of Tibetan and Euro-American experiences. Journal of Transpersonal Psychology, 25, 59-110.

Epstein, L. (1982). On the history and psychology of the das-log. Tibet Journal, 7(4), 20 85.

Farr, S.S. (1993). What Tom Sawyer learned from dying. Norfolk, VA: Hampton Roads. 
Fremantle, F., and Trungpa, C. (Eds.). (1975). The Tibetan book of the dead. Berkeley, CA: Shambhala.

Gallup, G., Jr., and Proctor, W. (1982). Adventures in immortality: A look beyond the threshold of death. New York, NY: McGraw-Hill.

Grof, S., and Grof, C. (1980). Beyond death. New York, NY: Thames and Hudson.

Grof, S., and Halifax, J. (1977). The human encounter with death. New York, NY: Dutton.

Lorimer, D. (1990). Whole in one: The near-death experience and the ethic of interconnectedness. London, England: Arkana.

Moody, R.A., Jr. (1975). Life after life Covington, GA: Mockingbird.

Reanney, D. (In press). The still point: Beyond the edges of consciousness. Melbourne, Australia: Hill of Content.

Ring, K. (1984). Heading toward omega: In search of the meaning of the near-death experience. New York, NY: Morrow.

Ring, K. (1992). The omega project: Near-death experiences, UFO encounters, and mind at large. New York, NY: Morrow.

Rinpoche S. (1992). The Tibetan book of living and dying. San Francisco, CA: HarperCollins.

Sutherland, C. (1992). Transformed by the light: Life after near-death experiences. New York, NY: Bantam.

Wells, A. (1993). Reincarnation beliefs among near-death experiencers. Journal of NearDeath Studies, 12, 17-34.

Zaleski, C. (1987). Otherworld journeys: Accounts of near-death experience in medieval and modern times. New York, NY: Oxford University Press. 